\title{
An Unexpected Complication of Bone Marrow Aspiration and Trephine Biopsy: Arteriovenous Fistula
}

\author{
Ilhami Berber ${ }^{\mathrm{a}} \quad$ Mehmet Ali Erkurt $^{\mathrm{a}} \quad$ Irfan Kuku $^{\mathrm{a}}$ Emin Kaya ${ }^{\mathrm{a}}$ Ramazan Kutlu ${ }^{\mathrm{b}}$ \\ Mustafa Koroglu ${ }^{a}$ Ali Yigit $^{c}$ Serkan Unlub \\ Departments of a Hematology, ${ }^{b}$ Radiology and ${ }^{C}$ Internal Medicine, Faculty of Medicine, Inonu University, \\ Malatya, Turkey
}

\section{Key Words}

Bone marrow aspiration - Trephine biopsy .

Arteriovenous fistula

\begin{abstract}
Objective: To report a case of arteriovenous fistula (AVF) following bone marrow aspiration and trephine biopsy. Clinical Presentation and Intervention: A 76-year-old man was diagnosed with acute myeloblastic leukemia. Pain and hematoma were detected in his left leg and hip 4 days after bone marrow aspiration and trephine biopsy. A pelvic arteriography was performed, and a diagnosis of AVF was made. Conclusion: This case shows that clinicians should be aware of AVF, especially in cases with refractory bleeding after bone marrow aspiration and trephine biopsy despite normal blood coagulation parameters.

๑) 2014 S. Karger AG, Basel
\end{abstract}

\section{Introduction}

Bone marrow aspiration and trephine biopsy are necessary procedures for the diagnosis of various hematological diseases. They are used to estimate prognosis and

\begin{tabular}{ll}
\hline KARGER & $\begin{array}{l}\text { ( ) 2014 S. Karger AG, Basel } \\
1011-7571 / 14 / 0234-0380 \$ 39.50 / 0\end{array}$ \\
$\begin{array}{l}\text { E-Mail karger@karger.com } \\
\text { www.karger.com/mpp }\end{array}$ & $\begin{array}{l}\text { This is an Open Access article licensed under the terms of the } \\
\text { Creative Commons Attribution-NonCommercial 3.0 Un- } \\
\text { ported license (CC BY-NC) (www.karger.com/OA-license), } \\
\text { applicable to the online version of the article only. Distribu- } \\
\text { tion permitted for non-commercial purposes only. }\end{array}$
\end{tabular}

assess responses to therapy. The posterior iliac crest is the most suitable region for performing these interventions. The complications associated with the procedures are rare $(0.05 \%)$ and could easily be missed due to the limited number of relevant reports in the literature. The most common and most serious complication is hemorrhage $[1,2]$. Arteriovenous fistula (AVF) is an abnormal connection between an artery and vein that is usually iatrogenic or results from trauma. The most common cause of femoral iatrogenic AVF is cardiac catheterization [3-5]. We hereby report a case of AVF secondary to bone marrow aspiration and biopsy.

\section{Case Report}

A 76-year-old male was admitted to our clinic with a diagnosis of acute leukemic transformation of myelodysplastic syndrome. Before treatment, bone marrow biopsy showed 30\% myeloblastic infiltration. Low-dose cytosine arabinoside $\left(20 \mathrm{mg} / \mathrm{m}^{2}\right)$ was started subcutaneously for 10 days, but this had not led to remission at bone marrow aspiration after two treatment cycles. As a secondline treatment, an induction treatment was started that consisted of cytosine arabinoside (100-200 $\mathrm{mg} / \mathrm{m}^{2} /$ day intravenously for 5 days) and idarubicin ( $12 \mathrm{mg} / \mathrm{m}^{2} /$ day intravenously for 2 days). On the 25th day of treatment, the leukocyte count was $4,500 / \mu \mathrm{l}$, the hemoglobin was $9.8 \mathrm{~g} / \mathrm{dl}$ and the platelet count was $48,000 / \mu \mathrm{l}$. A 

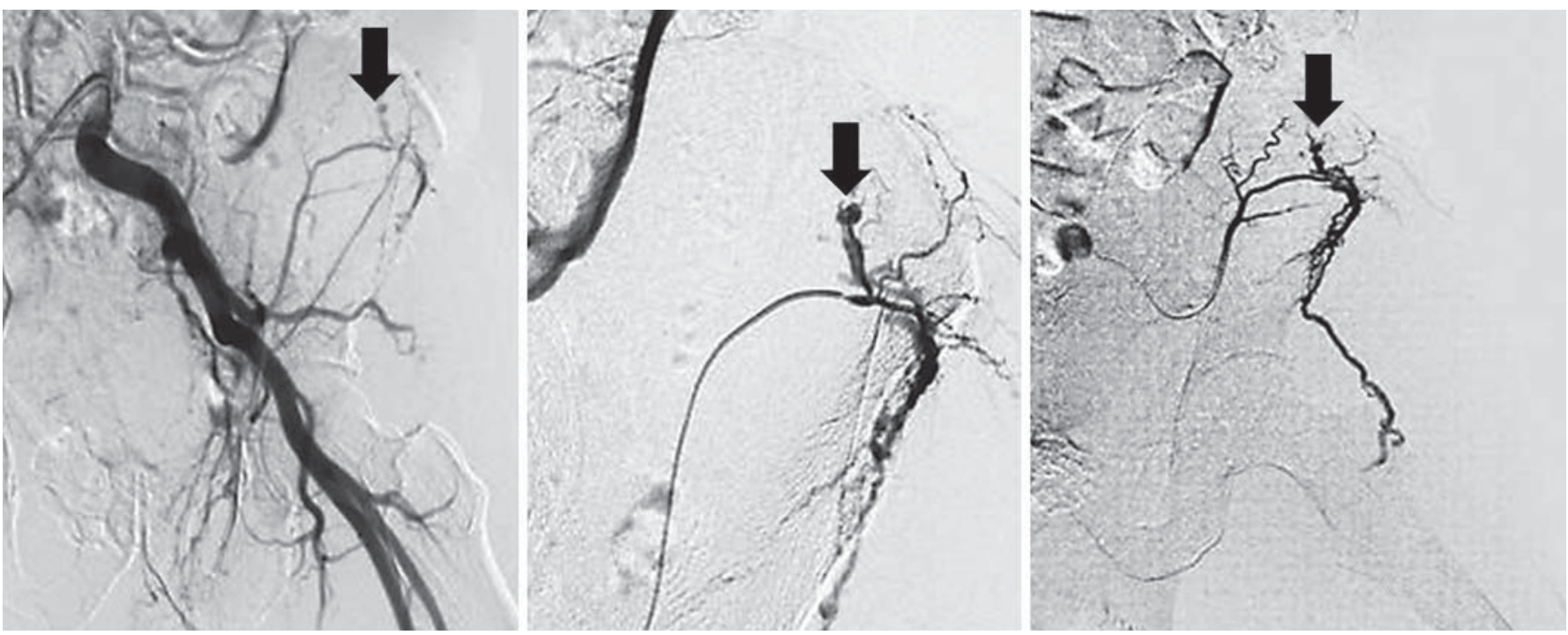

Fig. 1. Angiogram images showing AVF (arrows) in the left superior gluteal artery after selective catheterization of the left internal iliac artery.

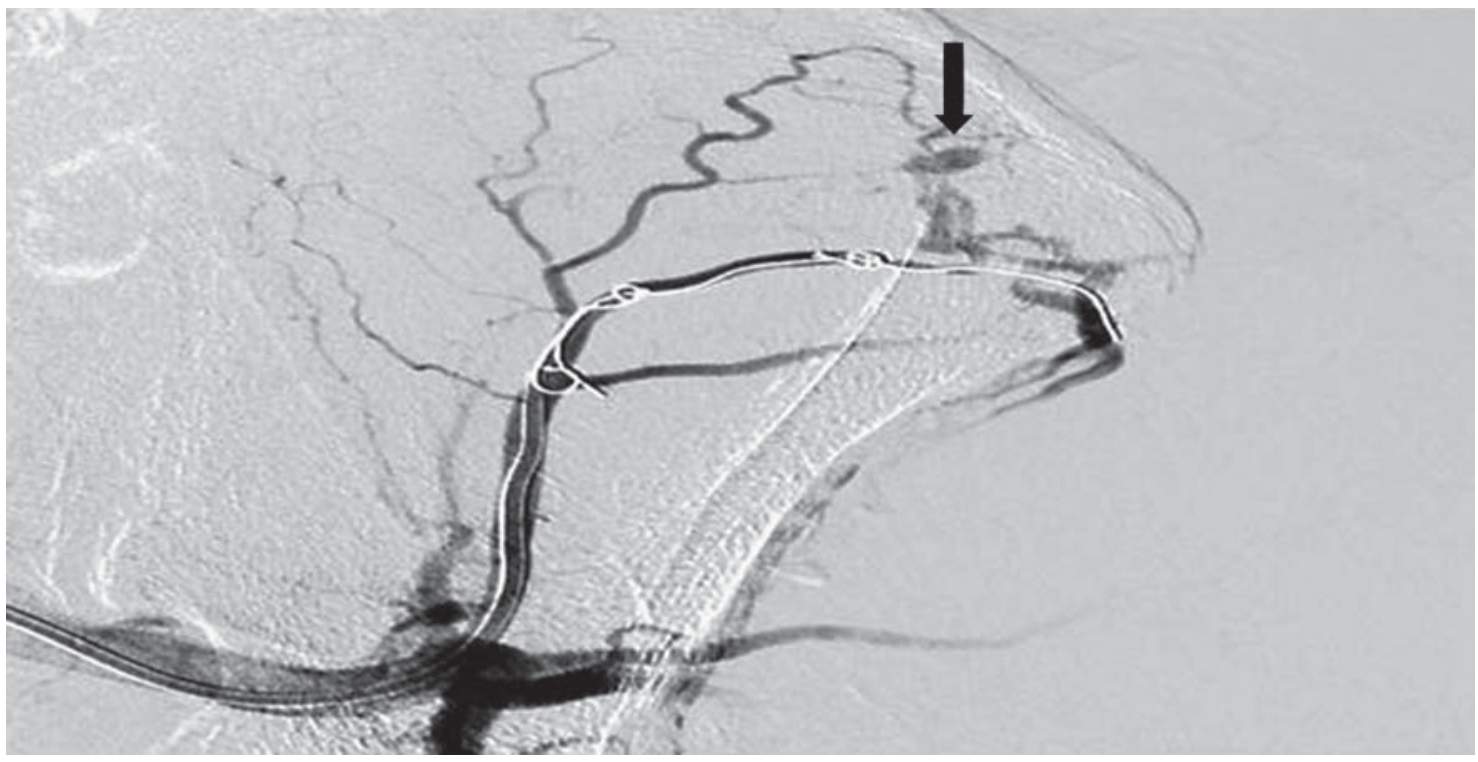

Fig. 2. Embolization of the left superior gluteal artery with a selective microcatheter.

peripheral blood smear showed 70\% neutrophils, 25\% lymphocytes and 5\% monocytes. Platelets showed 4-5 sets of clusters and erythrocyte morphology was normochromic and normocytic. To assess the state of remission, bone marrow aspiration and biopsy were performed from the left posterior iliac fossa at the rear left side of the iliac crest under local anesthesia and sterile conditions. Immediately after the bone marrow sample was taken, pressure was applied on the biopsy region with sterile gauze for $10 \mathrm{~min}$ and bleeding was controlled. There was no evidence of bleeding or infection at the biopsy site on the day after the procedure. Four days later, the patient presented with severe pain and diffuse bruises on his left buttock. Doppler ultrasonography showed a fluid collection in the back of the left thigh, reaching a depth of $2.7 \mathrm{~cm}$ (organized hematoma). The patient was not using any medication that could potentially lead to bleeding, e.g. aspirin or warfarin. The patient needed daily transfusions of red blood cell concentrate. To keep the prothrombin time at $11 \mathrm{~s}$, the partial thromboplastin time at $25.9 \mathrm{~s}$ and fibrinogen and platelet levels within a normal range, platelet suspensions and fresh frozen plasma support were given. Despite a platelet count of $88,000 / \mu \mathrm{l}$ and normal coagulation parameters, the bleeding did not stop. So an arterial angiography was performed to assess the arterial tree of the lower extremity. An 

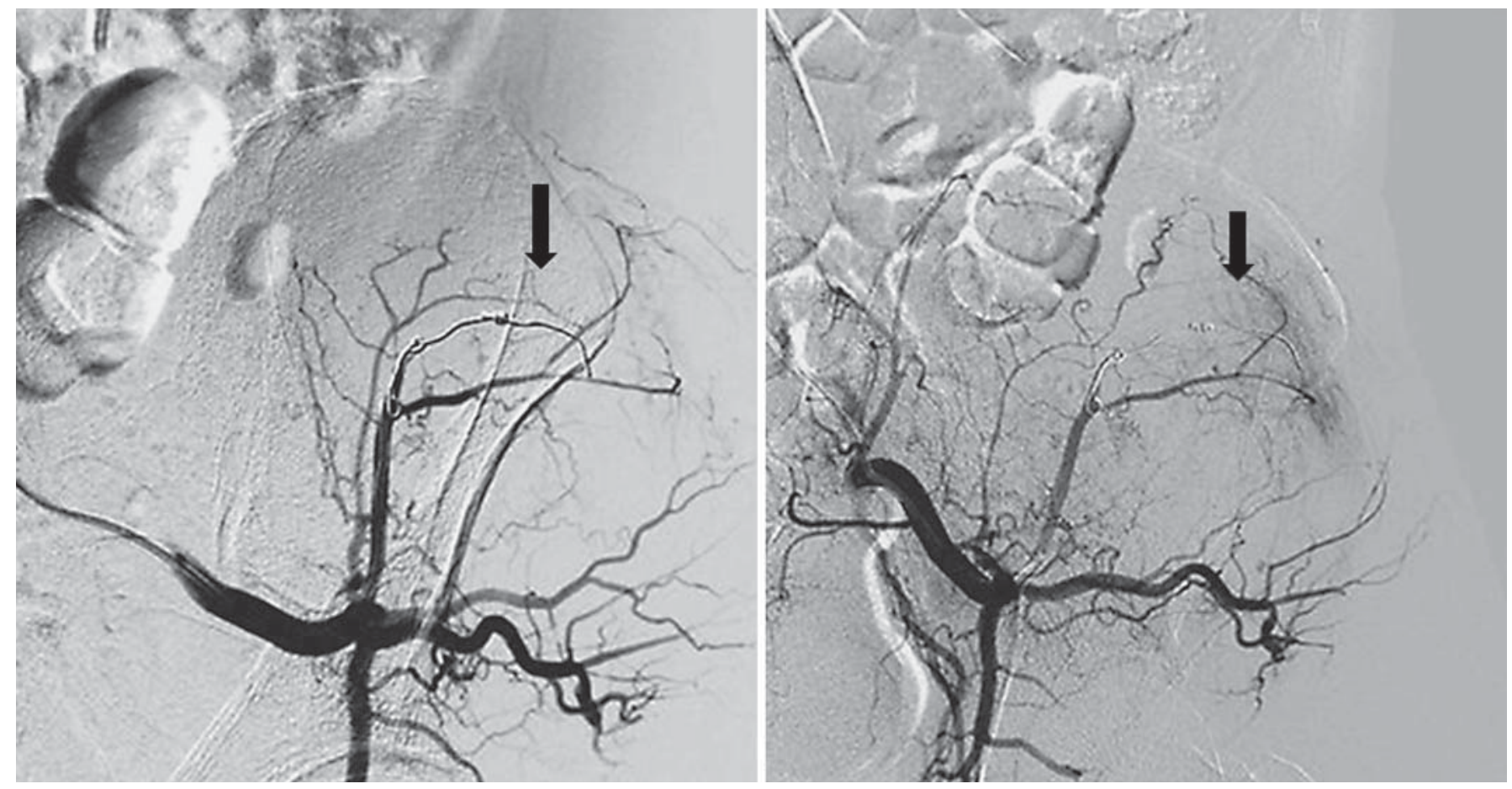

Fig. 3. Angiogram images not showing AVF after successful embolization with a shifted coil.

AVF was observed in the left superior gluteal artery after selective catheterization of the left internal iliac artery in the region corresponding to the bone marrow aspiration and biopsy site (fig. 1). Selective embolization was achieved in the same session and the bleeding stopped (fig. 2, 3).

Written informed consent was obtained from the patient's next-of-kin for publication of this case report and the accompanying images. Ethical approval was obtained from the Institutional Ethics Committee.

\section{Discussion}

This was a case of an iatrogenic AVF complication that resulted from bone marrow aspiration and simultaneous bone marrow biopsy performed on the left posterior/anterior iliac crest. No complications developed immediately after the procedure. The rarity of this case is shown in a study on 19,259 procedures in which only $16(0.08 \%)$ complications were reported [1]. Only 11 of these were hemorrhagic complications; others included infection in 2 patients and resistant pain in 2 patients. The procedure in another patient was complicated by a serous discharge from the wound site for 6 days [6]. Another case series that can confirm the rarity of this case comprised 20,323 procedures where only $15(0.07 \%)$ patients experienced complications: 9 had hemorrhage, 3 had severe pain, 1 had an anaphylactic reaction, 1 had severe aortic stenosis and 1 had a fracture on the biopsy side [2]. Sarigianni et al. [7] reported a case of hematoma in the buttock region that complicated combined procedures of bone marrow aspiration with biopsy in an 85-year-old patient. Arellano-Rodrigo et al. [8] reported on a patient with myelofibrosis who experienced severe retroperitoneal bleeding that was treated with selective arterial embolization following bone marrow biopsy. Neesse et al. [9] published an article on the significance of retroperitoneal hemorrhage following bone marrow aspiration. They reported that arterial embolization can be performed in cases with resistant bleeding. In our patient, refractory bleeding despite normal coagulation parameters suggested a vascular pathology, and arterial angiography was carried out. Currently, conventional angiography continues to be the gold standard for the evaluation of arteriovenous malformations, and it guides the assessment of options for endovascular treatment [10]. The resulting AVF in our case was successfully treated with transcatheter embolization. 


\section{Conclusion}

This case showed that clinicians should be aware of AVF, especially in cases with refractory bleeding after bone marrow aspiration and trephine biopsy despite normal blood coagulation parameters.

\section{Acknowledgements}

The authors thank all the physicians of the Turgut Ozal Medical Center as well as the patient who gave informed consent for the publication of personal information.

\section{References}

1 Bain BJ: Bone marrow biopsy morbidity and mortality. Br J Haematol 2003;121:949-951.

$\checkmark 2$ Bain BJ: Morbidity associated with bone marrow aspiration and trephine biopsy - a review of UK data for 2004. Haematologica 2006;91: 1293-1294.

3 Farid A, Sullivan TM: Aortocaval fistula in a ruptured inflammatory abdominal aortic aneurysm. J Cardiovasc Surg 1996;37:561-565.

$\checkmark 4$ Hammad FT, Shawish F, Kazim E: Congenital pelvic arteriovenous malformation presenting with urinary retention: a case report. Med Princ Pract 2011;20:294-296.
5 Noory E, Rastan A, Schwarzwälder U, et al: Retrograde transpopliteal recanalization of chronic superficial femoral artery occlusion after failed re-entry during antegrade subintimal angioplasty. J Endovasc Ther 2009;16: 619-623.

6 Bain BJ: Bone marrow biopsy morbidity: review of 2003. J Clin Pathol 2005;58:406-408.

7 Sarigianni M, Vlachaki E, Chissan S, et al: Haematoma caused by bone marrow aspiration and trephine biopsy. Hematol Rep 2011; 3:e25.

8 Arellano-Rodrigo E, Real MI, Muntañola A, et al: Successful treatment by selective arterial embolization of severe retroperitoneal hemorrhage secondary to bone marrow biopsy in post-polycythemic myelofibrosis. Ann Hematol 2004;83:67-70.
9 Neesse A, Kalinowski M, Walthers EM, et al: Clinical management of massive retroperitoneal hemorrhage after bone marrow biopsy. Leuk Lymphoma 2009;50:475-477.

10 Yilmaz S, Erdoğan A, Lüleci E: Transvenous embolisation and stent placement for an internal iliac arteriovenous fistula with central iliac vein occlusion. J Vasc Interv Radiol 2004; 15:399-404. 